\title{
Palliative Care Nursing Development in the Middle East and Northeast Africa: Lessons From Oman
}

\author{
Jeannine M. Brant ${ }^{1} \cdot$ Manal Al-Zadjali $^{2}$ · Faiqa Al-Sinawi ${ }^{3} \cdot$ Tayreez Mushani ${ }^{4} \cdot$ Susan Maloney-Newton ${ }^{5}$. \\ Ann M. Berger ${ }^{6} \cdot$ Regina Fink ${ }^{7}$
}

Accepted: 28 May 2021 / Published online: 15 June 2021

(c) American Association for Cancer Education 2021

\begin{abstract}
Nurses are on the frontline of palliative care, and in some countries, are the only contact for patients and families facing life-threatening illness. The Oman Cancer Association in the Sultanate of Oman, in collaboration with the Middle Eastern Cancer Consortium and the Oncology Nursing Society, led a palliative care initiative over the past decade to better integrate palliative care into the health care system. Components of this initiative include integrating palliative care into the health care curricula and providing palliative care education to over 400 nurses and other health care professionals within Oman. The four-part education series includes the following courses: (1) Foundations of Palliative Care, (2) Advanced Concepts in Palliative Care, (3) Palliative Care Leadership, and (4) Palliative Care Research. Additional participants from 17 different countries in the Middle East and northern Africa also attended the training. Twenty of the trainees who were considered palliative care leaders in their countries then participated in a Train the Trainer course. This group trained the last cohort of health care professionals in Oman and then took learned concepts and strategies back to their respective countries in order to provide country-wide education and build palliative care capacity in the region. Outcomes include the development of palliative care units, quality improvement projects that improved care, and advocacy projects to increase opioid availability within some countries. The collaborative continues its work and connections through social medial, email, and virtual collaboration. Other countries can use this model to permeate palliative care within their regions.
\end{abstract}

Keywords Palliative care $\cdot$ Cancer $\cdot$ Global health $\cdot$ Education $\cdot$ Train-the-trainer

The goal of palliative care is to improve quality of life for patients with serious and often chronic, life-limiting illness regardless of disease extent or need for additional therapies

Jeannine M. Brant

JBrant@BillingsClinic.org

1 Collaborative Science \& Innovation Department, Billings Clinic, Billings, MT, USA

2 Higher Institute of Health Specialties, Ministry of Health, Muscat, Sultanate of Oman

3 Oman Cancer Association, Muscat, Oman

4 Aga Khan University School of Nursing \& Midwifery, Nairobi, Kenya

5 The Medical Affairs Company (TMAC), Dayton, OH, USA

6 College of Nursing, University of Nebraska Medical Center, Omaha, NE, USA

7 School of Medicine and College of Nursing, University of Colorado Anschutz Medical Campus, Aurora, CO, USA
$[1,2]$. Palliative care emphasizes high-quality pain and symptom assessment and management, while incorporating psychosocial and spiritual care focusing on patient/family needs, values, preferences, and cultural beliefs. Palliative care is a philosophy of care that may be delivered by nurses and other health care professionals provided they are educated and skilled through appropriate learning opportunities; it also may be provided by tertiary palliative care specialists to patients with complex problems [3]. It is an important subspecialty that has taken hold in many developed countries over the past three decades; however, a need exists to provide palliative care to all persons globally.

The 2015 Quality of Death Index studied palliative care across the world ranking many Middle Eastern and East African countries at the bottom of the scale [4]. In regard to pain relief, an important component of palliative care, the Global Atlas of Palliative Care suggests access to opioid medications is a substantial problem worldwide [5]. Numerous countries $(\sim 80 \%)$ are not able to provide optimal pain 
relief for patients at the end of life since they utilize little to no opioids to manage pain. Lastly, access to palliative care is a human right that needs to be formally acknowledged by all countries with a plan for the provision of comprehensive palliative care by appropriately educated nurses and other health care professionals [6].

Nurses are on the frontline of palliative care. More than any other health care professionals, nurses devote the most time caring for patients and family caregivers who are coping with the trials of serious, life-limiting illnesses [7, 8]. Nurses may even be the only contact for patients and families and are in a powerful position to advocate for opioid use and provide patient and family education to dispel myths surrounding opioid use. Additionally, while physicians are in the position to prescribe opioids in many countries, many low- to middle-income countries (LMICs) lack the critical mass of physicians and nurses are the frontline providers of palliative care. In some cases, palliative care is delivered solely by nurses who have been given prescriptive authority in their respective countries (e.g., Uganda) [9]. The role of the nurse also includes advocating for health care policies that impact the delivery of palliative care and the availability of opioids and other essential components of care, providing leadership in community palliative care formation, and in conducting palliative care research [10]. This paper describes an innovative palliative care nursing education program that has been developed, implemented, and sustained in Oman and expanded throughout the Middle East and North Africa. Examples are provided that illustrate tangible outcomes of this collaboration.

\section{Palliative Care in Oman}

Early efforts to integrate palliative care in Oman were sporadic and limited. While palliative care content was incorporated into the health professional education curricula, a formal palliative care training program was lacking. In 2011, the Oman Cancer Association (OCA), through support from the Ministry of Health $(\mathrm{MOH})$, collaborated with the Middle Eastern Cancer Consortium (MECC) and the Oncology Nursing Society (ONS) to unite health care professionals from many Middle Eastern countries to build palliative care

Table 1 Efforts to promote palliative care in Oman

Date Palliative care in Oman

2011 - The first course on Foundations of Palliative Care was initiated in Oman. The course was coordinated by MECC and taught by nurses from the Oncology Nursing Society.

O Attendees were from Oman, Cyprus, Egypt, Israel, Jordan, Iraq, Palestine, Turkey, Pakistan, United Arab Emirates, and Yemen

2012 - Advanced Palliative Care Courses were conducted

O Same attendees from 2011

- Royal Hospital in Muscat, Oman sent two staff nurses to California, USA for a training program in palliative care.

- Nurses trained in palliative care implemented their action plans.

2013 • Foundations and Advanced Palliative Care Courses were conducted for a second cohort of nurses

2014 - Nurse leaders attended the Middle Eastern Cancer Consortium Cancer Conference in collaboration with NCI in Ankara, Turkey

- BSc (Hons) Community Health Nursing students organized a scientific day to promote palliative care among health care workers and organized an outreach program to educate the public about palliative care

- Palliative care was approved by the Sultanate of Oman Ministry of Health resorting it administratively under primary health care

- Palliative care was provided as an outpatient service in the National Oncology Center, Royal Hospital. The clinic focused primarily on pain and symptom management. A doctor and a nurse were assigned to the clinic seeing palliative care patients 1 day each week

2015 - Another group of Omani nurses were trained on Foundations of Palliative Care by OCA and MOH in collaboration with MECC and ONS

- Attendees expanded to include Afghanistan, Iran, Qatar, Kenya, Tanzania, and Zambia

- The $7^{\text {th }}$ Muscat international oncology conference was attended by 450 health care professionals

2016 - Nurses were trained in Advanced Palliative Care by OCA and MOH in collaboration with MECC and ONS

- The $8^{\text {th }}$ Muscat international oncology conference was attended by 400 health care professionals

- Primary health care physicians were trained in palliative care

- Nurses who attended the palliative care courses were trained in palliative care leadership and research in palliative care

- OCA organized a leadership conference for health care professionals

- OCA in collaboration with the MOH and University of Nebraska implemented the first research to publication workshop for health care professionals

- OCA organized a palliative care workshop for journalists

- OCA organized a palliative care awareness course for volunteers

- Two palliative care training workshops were conducted in Royal Hospital

2017 - OCA organized a spiritual care course for participants from the Middle Eastern and East African region

- OCA organized a Train the Trainer Course, which was delivered by ONS for Omani and international nurse leaders who then provided the Foundations of Palliative Care Course

- OCA organized a second Train the Trainer Course the Advanced Palliative Care, Leadership, and Research Courses 
capacity. Palliative care education was offered to nurses and other health care professionals in the region. Since then, the OCA has exerted great effort in training nurses and other health care professionals in palliative care with the support of its partners (Table 1) [11].

The authors of this paper met during this collaboration and have led this collaboration over the past decade. Professor Michael Silbermann, the Executive Director of the MECC, initially brought this group together and organized the early training efforts. Dr. Al-Zadjali and Ms. Al-Sinawi served as the nursing leaders from Oman, and Ms. Maloney-Newton was a nurse educator from the ONS in the USA since the beginning of the initiative in 2012. Drs. Brant and Fink were brought into the collaborative in 2013 through the Oncology Nursing Society, and Dr. Brant was appointed as leader of the ONS team shortly thereafter. Both Drs. Brant and Fink were appointed to a National Cancer Institute (NCI) committee that represented Palliative Care in the Middle East. Ms. Mushani, a nursing leader and assistant professor in Kenya, entered the collaborative in 2015 when the educational reach expanded into northern Africa. And Dr. Berger taught research course components at a training in 2017. In addition to the meetings in Oman, the authors from this paper and other nurse leaders from this collaborative engaged in education and strategy meetings virtually and in Istanbul and Ankara, Turkey. This nursing collaborative continues to share experiences through social media and through virtual meetings.

\section{Landscape of Oman}

The Sultanate of Oman is a Middle Eastern Country located in the southeast coast of the Arabian Peninsula. Oman is approximately $309,500 \mathrm{~km}^{2}$ (i.e., $120,00 \mathrm{mi}^{2}$ ) in size with a population around 4.5 million including foreigners and residents. The majority of the population in Oman is young, between 15 and 64 years of age (40\% of the population), with a life expectancy of 75 and 79 years for males and females respectively [12]. Oman is an ethnically diverse country and most of the people in the country are Muslim [13]. According to The World Economic Forum, Oman is considered the $9^{\text {th }}$ safest country to live in around the world [14].

The safety of Oman as well as the OCA's well-developed relationships with international partners, governmental and non-governmental organizations has created an environment that supports palliative care education throughout the East Mediterranean region.

\section{Global Partnerships}

Palliative care educational needs are not unique to the Middle East. The World Health Organization (WHO) estimates that at present, palliative care services are only received by
$14 \%$ of the people who need them with the greatest needs being in low- and middle-income countries such as those of sub-Saharan Africa [15]. The African continent faces the most severe global shortage of health care providers, and estimates needing 4.2 million health care workers to amend the shortfall [16, 17]. Two East African countries, Kenya and Tanzania, reflect the current African situation.

Challenges in the provision of palliative care in Kenya and Tanzania include a lack of adequate health human resources, poor infrastructure, limited access to essential medications, insufficient number of trained palliative care providers, and a lack of palliative care education. Health systems face additional educational challenges including the high cost of utilizing and consulting with expert faculty to teach palliative care concepts or sending local professionals to distant sites for training $[16,17]$.

The current model of the OCA-ONS partnership is therefore a timely and welcome initiative to meet this challenge. Through this initiative, nurse educators from Kenya and Tanzania were invited to participate in training offered to nurses from Oman and other Middle Eastern countries. The model enabled participants to receive four palliative care courses over 1 year delivered by international oncology and palliative care nursing experts. In addition, participants networked with other regional and international professionals, made new contacts, discussed challenges, exchanged ideas, and received much needed mentorship.

This level of engagement is not always available to participants in their host countries. Episodic workshops delivered by visiting professionals seldom result in long-term sustainability and solid program development. The OCAONS initiative with its focus on long-term capacity building enables participants to access training in a stepwise fashion, implement small changes in the workplace, identify issues, and then receive guidance and feedback at future sessions. In this way, they are able to implement more permanent changes in the delivery of palliative care around the region.

The other, perhaps unintended benefit of this partnership is the opportunity for participants to set up networks to exchange knowledge and ideas, establish joint projects, and derive contextually relevant solutions to common challenges. This partnership is an example of how organizations and individuals with a shared vision can partner to impact the lives of patients across several countries, some of which face grave challenges in the provision of palliative care. Ongoing virtual communication has fostered relationships and attainment of goals set during the training.

\section{Palliative Care Curriculum}

Nearly 400 nurses and other health care professionals from Oman and 11 countries throughout the Middle East and Eastern Africa have successfully completed palliative 
care training. The training, conducted by nurses from the Oncology Nursing Society, comprised five separate courses: Foundations of Palliative Care, Advanced Palliative Care, Leadership and Research in Palliative Care, and a Train the Trainer for select representatives from each of the represented countries across the Middle East and northeast Africa.

The Foundations Course delivers basic principles of palliative care and provides nurses with basic knowledge about the definition and scope of palliative care, pain, and symptom management principles; cultural, psychosocial, and spiritual care; the interdisciplinary palliative care team, ethics related to palliative care, and compassion fatigue. The Advanced Course provides in-depth coverage of the same topics as above but also includes family care giving, management of patients with substance use disorders, strategies to increase opioid availability, and how to implement palliative care into the hospital, ambulatory, and home settings. Additionally, the Advanced Course enables nurses to plan and implement evidencebased changes and improvements in palliative care services within their clinical practices, institutions, and communities. A variety of interactive teaching strategies called Liberating Structures are used to meet the learning needs of diverse participants and include facilitated group discussions, case study analyses, role play or improvs, and development and presentation of evidence-based projects. These strategies are used throughout the courses to involve every nurse attendee, unleash creativity, and engage in group problem solving to collaboratively achieve better results than didactic education can achieve alone. An overview of these activities is included in Table 2 [18]. Overall, the Foundations Course is intended to teach the basics of palliative care, while the focus of the Advanced Course is to design palliative care initiatives and programs and develop plans for program implementation within the health care setting or community.

With palliative care being more integrated into the region's health care systems, the OCA recognized the need to further develop the course participants as leaders in their region, to encourage them to "step up" and lead change, facilitate innovation, and provide advocacy for patients and families. There is also a need for them to contribute to new knowledge through research, and to create a culture of inquiry in which questions are explored and novel interventions tested, with the hope of improving palliative care in the Middle East and East Africa. The research course addresses this need. At the completion of the combined Leadership and Research Course, each participant develops an individual or group research proposal that can potentially be further refined for submission to an Institutional Review Board. Table 3 includes a list of proposed research studies. A leadership development plan is also crafted for personal use and allows nurses and other participants to reflect on their personal leadership strengths and opportunities for improvement.

After seeing the positive results of the ongoing training and palliative care being implemented in Oman and the surrounding countries, a need existed to make the training sustainable. A "Train the Trainer (TTT) workshop" was thus implemented in February, 2017. The overarching goal was to establish nurse and other health care leaders who would build capacity in their countries by disseminating palliative care knowledge, evidence-based practice initiatives, and bring palliative care research to their respective countries. ONS faculty provided the two-day TTT course for Middle Eastern nurse leaders who had completed all four palliative care courses. These nurses are responsible for carrying forward the mission of progressing palliative care throughout the region.

Following the TTT course, 20 nurse leaders then taught the Foundations of Palliative Care Course to 160 nurses and health care professionals from the region. The course was deemed successful, as evidenced by the impactful presentations from trainees who delivered didactic content of the course and led small group activities. A positive response was garnered from trainees and participants.

\section{Sustainability}

Essential to the long-term goal of partnerships between high-income countries and low- to middle-income countries (LMIC) to improve cancer care includes development of a sustainable program [19]. The TTT program which was previously discussed is one sustainability effort. Additionally, programs should include training nurses to deliver palliative care as their full-time practice, which does not always happen in the region. Nurses are often assigned to a variety of units; therefore, they lack specialization in any one area. Service delivery issues, such as a shortage of qualified nursing staff, need to be identified as a health system constraint and addressed in LMICs. For continuity, a long-term relationship among OCA, ONS, and other partners is essential, and a 5-year agreed-upon plan is necessary to solidify the efforts [20]. Relationships are also key in maintaining longterm relationships, and encouragingly, the group maintains contact ongoing through its group WhatsApp chat.

Cancer registries are another essential sustainable effort to collect data that demonstrate useful and reliable information specific to the population of cancer patients who receive palliative care. The creation of a data bank is an important first step in improving cancer care in Middle Eastern countries [21]. If data are collected reliably, summarized, and analyzed by qualified researchers, the information obtained will demonstrate the short-term outcomes and identify 


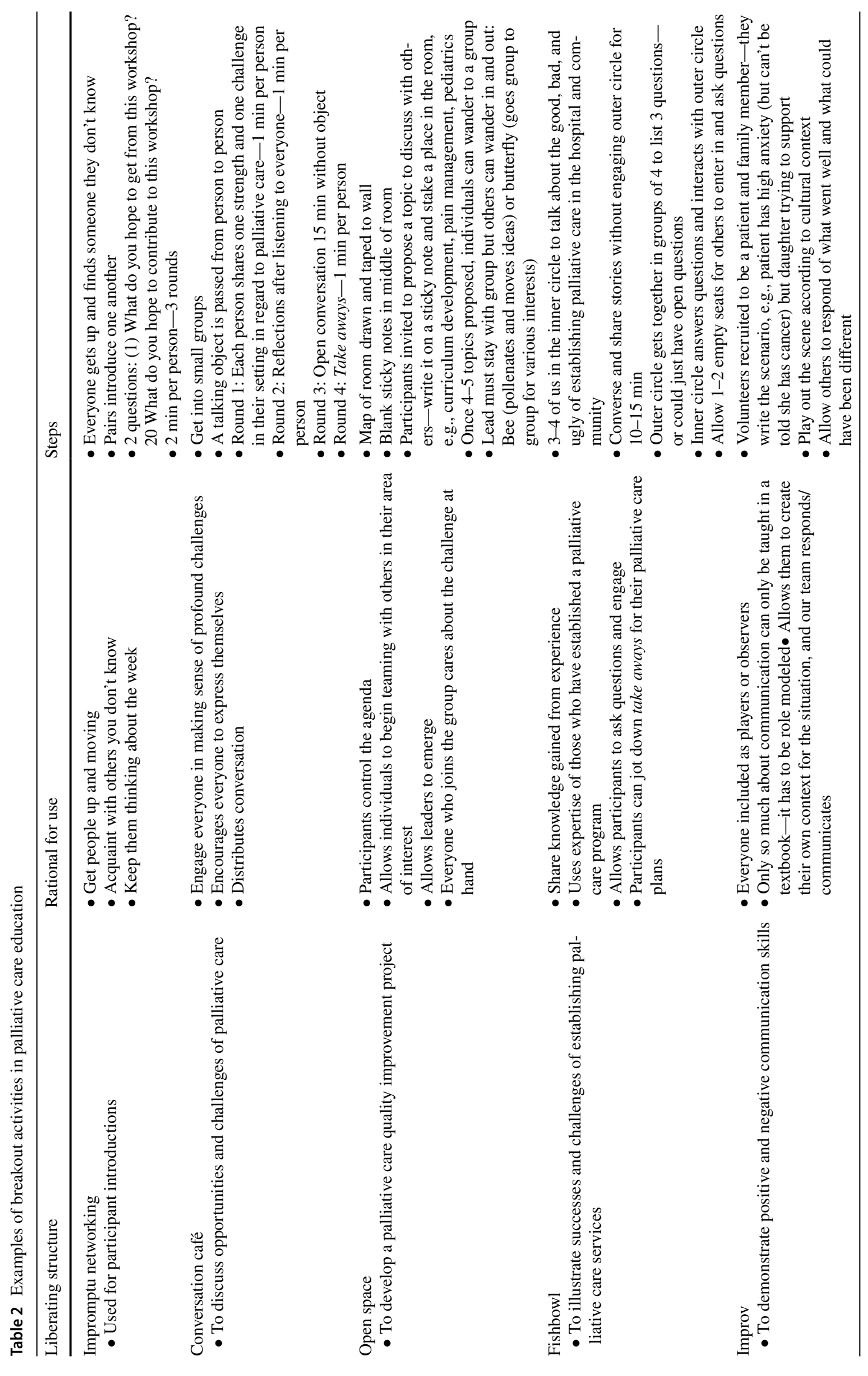




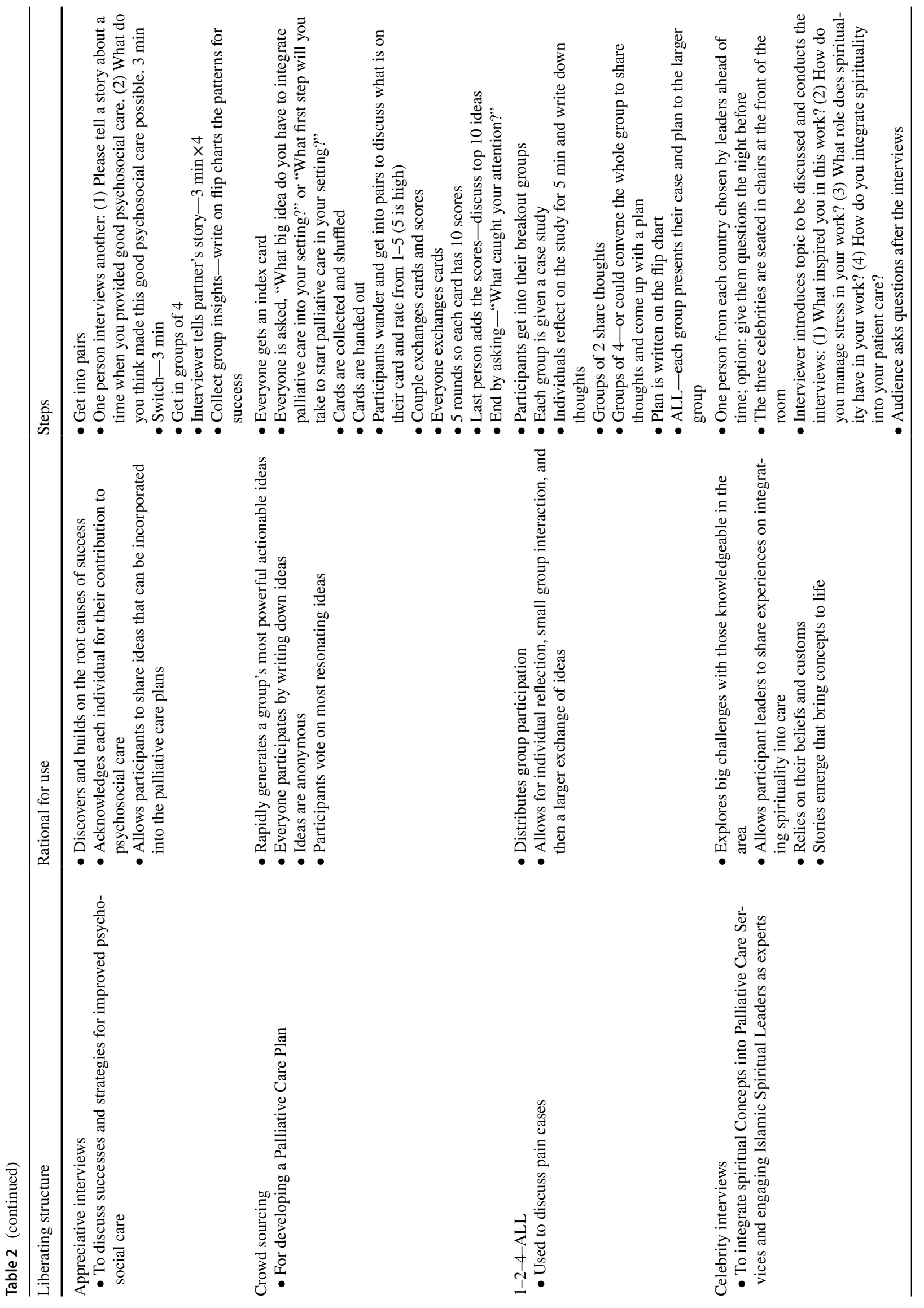


strategies needed to achieve long-term goals for sustainability. For sustainability, registries need to be streamlined for efficiency [22]. Additionally, ongoing involvement in the World Health Organization (WHO) palliative care program is important to make progress in cancer prevention and control in the region [23].

Omani, Middle Eastern, and East African nurse leaders are critical to the success of the partnership described in prior sections of this paper. That is the major reason why more than 400 nurses have attended the Palliative Care Nursing and Research and Leadership courses held in Oman in recent years. Each nurse or health care professional returned to their position with new knowledge, skills, and attitudes about palliative nursing care. When disseminating their learning with peers, they influence the current culture of nursing care and help prepare peers for practice changes that can be sustained.

Twenty nurse leaders also completed the TTT course and delivered a four-day Foundations in Palliative Care Course. Mentorship of emerging Omani nurse leaders will continue to occur following these activities, along with other programs to improve cancer and palliative nursing care. Expanding onsite and online programs and opportunities to train nurses to deliver palliative cancer care will positively influence sustainability efforts.

Significant challenges face the ongoing implementation and sustainability of palliative care in Oman and in Middle Eastern, and East African countries. Some of the challenges and suggested solutions are included in Table 4.

\section{Future Directions}

Abundant opportunities exist for the future. The OCAONS model for palliative care can expand into new regions, including rural areas and sub-Saharan Africa. Primary palliative care should be made available to all persons, and must reach smaller hospitals, home care settings, and clinics throughout Oman and other regions.

In addition to educating nurses, other interdisciplinary team members will be invited to the educational and training opportunities including pharmacists, social workers, spiritual care advisors and chaplains, physicians, and other health care professionals. Interdisciplinary training can enhance teamwork and foster respect for each individual's role on the palliative care team.

Increasing public awareness of palliative care is another important direction for the future. Patients and health care professionals alike continue to be confused about the definition of palliative care. Ensuring and clarifying that palliative care is not hospice or caring for patients exclusively at the end of life is essential, rather, an understanding should exist that palliative care is care for patients with serious, life-limiting illnesses and their family caregivers. 
Table 3 Proposed research questions

\begin{tabular}{|c|c|}
\hline Topic & Research question \\
\hline Beliefs and Pain & $\begin{array}{l}\text { What are the knowledge and attitudes about pain management and addiction among patients and health care } \\
\text { professionals in the Middle East and how does it affect opioid prescribing? }\end{array}$ \\
\hline Family Caregiving & What are the experiences of family caregivers of patients with advanced cancer in Oman? \\
\hline Oral Mucositis & $\begin{array}{l}\text { Does a nursing education intervention about mouth care prevent or improve oral complications in patients } \\
\text { undergoing chemotherapy? }\end{array}$ \\
\hline Psychosocial and Psychometrics & What are the psychometric properties of the post-traumatic growth scale in Muslims diagnosed with cancer? \\
\hline Spirituality and Pain & Is there a relationship between pain intensity and spirituality among Middle Eastern patients with cancer? \\
\hline Survivorship & What are the needs of young women with breast cancer who have completed initial cancer treatment? \\
\hline Survivorship & Is there a relationship between breast cancer recurrence and exercise? \\
\hline Workforce & $\begin{array}{l}\text { What is the level of knowledge of oncology nurses regarding chemotherapy side effects and does the degree of } \\
\text { knowledge influence patient and caregiver home management of side effects? }\end{array}$ \\
\hline Workforce & What are the emotional experiences among Omani nurses who care for dying patients? \\
\hline
\end{tabular}

Table 4 Palliative care challenges and solutions

\begin{tabular}{|c|c|}
\hline Challenges & Solutions \\
\hline $\begin{array}{l}\text { - Need to recognize the program within the health care system } \\
\text { - Lack of resources } \\
\text { - Lack of trained personnel }\end{array}$ & $\begin{array}{l}\text { Program approval within the health care system with an allotted budget for } \\
\text { running the program, the educational trainings, and other related activities }\end{array}$ \\
\hline - Lack of patients' awareness & Community outreach activities and raising patients' awareness \\
\hline $\begin{array}{l}\text { - Poor communication between health care professionals and } \\
\text { patients and families }\end{array}$ & Provide appropriate and culturally relevant training to health care professionals \\
\hline - Stigma of cancer and palliative care & Community outreach activities and health education \\
\hline - Lack of governmental support & $\begin{array}{l}\text { Proper introduction of the program to governmental stakeholders to gain trust } \\
\text { and approval }\end{array}$ \\
\hline - Restricted access to opioids & $\begin{array}{l}\text { Conversations with the } \mathrm{MOH} \\
\text { Proper training and clear policies for opioid availability and administration }\end{array}$ \\
\hline - Distance & $\begin{array}{l}\text { Develop Train the Trainer capacity to spread palliative care throughout the } \\
\text { region }\end{array}$ \\
\hline - Palliative care currently focused in tertiary care areas & Introduce palliative care in all health care settings and within the community \\
\hline - Instability/war in some Middle Eastern countries & $\begin{array}{l}\text { Bring those health care professionals to a safe area for palliative care training } \\
\text { Imbed palliative care into the health services that can be provided despite the } \\
\text { political situation of the country }\end{array}$ \\
\hline - Additional funding & $\begin{array}{l}\text { Encourage sponsorship from different organization with the same interest, } \\
\text { e.g., conducting fundraising activities or support from non-governmental } \\
\text { organizations }\end{array}$ \\
\hline
\end{tabular}

Finally, leaders should continue to work with governments, ministries of health, and palliative care associations to improve opioid availability for pain management [24, 25]. Other pharmaceuticals are also necessary to improve symptom management and alleviate suffering for patients along the disease trajectory.

Overall, the excitement of this work has permeated the region. While much has been accomplished, much more work remains. As a fourteenth century philosopher noted, "It is important not to allow ourselves to be put off by the magnitude of others' suffering. The misery of millions is not a cause for pity. Rather it is a cause for compassion." This compassion will continue to drive these efforts forward and make a positive impact on the quality of lives of patients with serious illness and their families. Under the foundation of MECC and within OCA's current leadership, continents and people are united to make this dream a reality.

\section{References}

1. World Health Organization. Palliative care fast fastsheet. WHO. http://www.who.int/mediacentre/factsheets/fs402/en/ Published 2018. Accessed 1 June 2018

2. World Health Organization. Integrating palliative care and symptom relief into primary health care: a WHO guide for planners, implementers and managers. World Health Organization. Published 2018. Accessed 2 Dec 2018 
3. Radbruch L, De Lima L, Knaul F et al (2020) Redefining Palliative Care-A New Consensus-Based Definition. J Pain Symptom Manag 60(4):754-764. https://doi.org/10.1016/j.jpainsymman. 2020.04.027

4. Economist Intelligent Unit. Quality of Death Index. The Economist Intelligent Unit Limited. https://www.eiuperspectives.econo mist.com/healthcare/2015-quality-death-index. Published 2015. Accessed 11 Mar 2017

5. Connor SR, Bermedeo MCS (2014) Global atlas of palliative care at the end-of-life. Worldwide Palliative Care Alliance, London

6. Ferrell B, Malloy P, Mazanec P, Virani R (2016) CARES: AACN's new competencies and recommendations for educating undergraduate nursing students to improve palliative care. J Prof Nurs 32(5):327-333

7. Silbermann M, Fink RM, Min SJ et al (2015) Evaluating palliative care needs in Middle Eastern countries. J Palliat Med 18(1):18-25

8. Brant JM, Fink RM, Thompson C et al (2019) Global survey of the roles, satisfaction, and barriers of home health care nurses on the provision of palliative care. J Palliat Med 22(8):945-960

9. Fraser BA, Powell RA, Mwangi-Powell FN et al (2018) Palliative care development in Africa: lessons from Uganda and Kenya. J Glob Oncol 4:1-10

10. Shamian J (2015) Global voice, strategic leadership and policy impact: global citizens, global nursing. Int Nurs Rev 62(1):4

11. Al-Zadjali M, Al Sinawi F, Al Touby S, Al Busaidi M, Al JF (2015) Palliative care nursing in Oman; moving towards palliative care nursing. J Palliat Care Med S5:40-44

12. World Health Organization. Countries: Oman. WHO. http://www. who.int/countries/omn/en/. Published 2017. Accessed 10 Mar 2017

13. Al-Zadjali M, Sinawi F, Sheeba M, Al Busaidi M, Al Jabri S, Silbermann M (2014) Community health nursing in Oman. Health Care Curr Rev 2-3. https://doi.org/10.4172/2375-4273.1000128

14. World Economic Forum. Travel and tourism vompetitiveness report. World Economic Forum. https://reports.weforum.org/ travel-and-tourism-competitiveness-report-2015/economies/\# economy $=$ OMN. Published 2015. Accessed 5 Mar 2017

15. World Health Organization. Assessing national capacity for the prevention and control of noncommunicable diseases: report of the 2015 global survey. WHO. http://apps.who.int/iris/bitstream/ handle/10665/246223/9789241565363-eng.pdf;jsessionid= D1D3B3189E532CC1568841C71 ADB818B? sequence $=1 \&$ TSPD_101_R0=13566a6a80ca155434ed42b63bf07773j1b00000 0000000000271617 a61ffff000000000000000000000000000 05b7de7fc0064dd669a. Published 2016. Accessed 20 May 2018

16. Liu JX, Goryakin Y, Maeda A, Bruckner T, Scheffler R (2017) Global health workforce labor market projections for 2030. Hum Resour Health 15(1):11

17. Rawlinson F, Gwyther L, Kiyange F, Luyirika E, Meiring M, Downing J (2014) The current situation in education and training of health-care professionals across Africa to optimise the delivery of palliative care for cancer patients. Ecancermedicalscience $8: 492$

18. Lipmanowicz H, McCandless K (2013) The surprising power of liberating structures. Lipmanowicz and McCandless, Seattle

19. Ribeiro RC, Antillon F, Pedrosa F, Pui CH (2016) Global pediatric oncology: lessons from partnerships between high-income countries and low- to mid-income countries. J Clin Oncol 34(1):53-61

20. Mills A (2014) Health care systems in low- and middle-income countries. N Engl J Med 370(6):552-557

21. Najjar H, Easson A (2010) Age at diagnosis of breast cancer in Arab nations. Int J Surg 8(6):448-452

22. Stillman FA, Kaufman MR, Kibria N, Eser S, Spires M, Pustu Y (2012) Cancer registries in four provinces in Turkey: a case study. Global Health 8:34

23. Khatib O, Aljurf M (2008) Cancer prevention and control in the Eastern Mediterranean region: the need for a public health approach. Hematol Oncol Stem Cell Ther 1(1):44-52

24. Lynch T, Connor S, Clark D (2013) Mapping levels of palliative care development: a global update. J Pain Symptom Manage 45(6):1094-1106

25. Cleary J, Silbermann M, Scholten W, Radbruch L, Torode J, Cherny NI (2013) Formulary availability and regulatory barriers to accessibility of opioids for cancer pain in the Middle East: a report from the Global Opioid Policy Initiative (GOPI). Ann Oncol 24(Suppl 11):xi51-59

Publisher's Note Springer Nature remains neutral with regard to jurisdictional claims in published maps and institutional affiliations. 